DIREITO PENAL

COMENTÁRIO À JURISPRUDÊNCIA

\title{
ROUBO CIRCUNSTANCIADO (ART. 157, I, CP): DESNECESSIDADE DE APREENSÃO E PERÍCIA NA ARMA DE FOGO E A DECISÃO DO STF (HC No 96.099): APLICAÇÃO DO PRINCÍPIO DA PROIBIÇÃO DA PROTEÇÃO INSUFICIENTE
}

GLAUCIO NEY SHIROMA OSHIRO

Promotor de Justiça Ministério Público do Estado do Acre, Brasil glaucio.oshiro@ac.gov.br

Em decisão publicada no DJ de 4 de junho de 2009, o Supremo Tribunal Federal (STF), em Plenário, no HC $\mathrm{n}^{\mathrm{o}} 96.099$, relatado pelo Ministro Ricardo Lewandowski, pacificou o tema sobre a desnecessidade de apreensão de arma de fogo e a consequente perícia para ser caracterizado o crime de roubo circunstanciado (art. 157, § $2^{\circ}$, inciso I, do Código Penal), quando presentes outros elementos que comprovam a utilização daquele tipo de arma. Na espécie, o paciente pretendia a exclusão da causa de aumento, tendo em vista que a arma de fogo não fora apreendida e, por consequência, não fora periciada, impossibilitando, assim, constatar a potencialidade lesiva do artefato, o que seria inafastável para configurar a majorante. Veja-se a ementa:

ROUBO QUALIFICADO PELO EMPREGO DE ARMA DE FOGO. APREENSÃO E PERÍCIA PARA A COMPROVAÇÃO DE SEU POTENCIAL OFENSIVO. DESNECESSIDADE. CIRCUNSTÂNCIA QUE PODE SER EVIDENCIADA POR OUTROS MEIOS DE PROVA. ORDEM DENEGADA. I - Não se mostra necessária a apreensão $e$ perícia da arma de fogo empregada no roubo para comprovar o seu potencial lesivo, visto que tal qualidade integra a própria natureza do artefato. II - Lesividade do instrumento que 
se encontra in re ipsa. III - A qualificadora do art. 157 , § $2^{\circ}$, I, do Código Penal, pode ser evidenciada por qualquer meio de prova, em especial pela palavra da vítima - reduzida à impossibilidade de resistência pelo agente - ou pelo depoimento de testemunha presencial. IV - Se o acusado alegar o contrário ou sustentar a ausência de potencial lesivo da arma empregada para intimidar a vítima, será dele o ônus de produzir tal prova, nos termos do art. 156 do Código de Processo Penal. $V$ - A arma de fogo, mesmo que não tenha o poder de disparar projéteis, pode ser empregada como instrumento contundente, apto a produzir lesões graves. VI - Hipótese que não guarda correspondência com o roubo praticado com arma de brinquedo. VII - Precedente do STF. VIII - Ordem indeferida. (STF, T. Pleno, HC $\mathrm{n}^{\circ}$ 96099, Rel. Min. Ricardo Lewandowski, julgado em 19/02/2009, DJ 04/06/2009, grifo nosso).

Votaram com o Ministro Ricardo Lewandowski os Ministros Marco Aurélio, Menezes Direito, Cármen Lúcia e Carlos Britto. Ausentes os Ministros Celso de Mello, Ellen Gracie e Joaquim Barbosa. Ficaram vencidos os Ministros Cezar Peluso, Eros Grau e o Presidente, Ministro Gilmar Mendes.

Sublinhe-se que, apesar de ausentes no julgamento, os Ministros Ellen Gracie e Joaquim Barbosa já se pronunciaram a respeito do tema no sentido do voto do relator no âmbito da $2^{\text {a }}$ Turma. Veja-se:

ROUBO. USO DE ARMA DE FOGO (CP, ART. 157, § 2', I). 1. A qualificadora de uso de arma de fogo (CP, art. 157, § $2^{\circ}$, I) independe da apreensão da arma, principalmente quando, como ocorreu nos autos, a arma foi levada pelos comparsas que conseguiram fugir. (STF, $2^{\mathrm{a}}$ T., HC 84032, Rel. Min. ELLEN GRACIE, DJ 30/04/2004). (grifo nosso).

HABEAS CORPUS. RECONHECIMENTO DA REINCIDÊNCIA COMO AGRAVANTE. MATÉRIA NÃO APRECIADA PELO SUPERIOR TRIBUNAL DE JUSTIÇA. NÃO CONHECIMENTO. CAUSA DE AUMENTO DE PENA PREVISTA NO ART. $157, \S 2^{\circ}, I, D O$ CÓDIGO PENAL. PRESCINDIBILIDADE DA REALIZAÇÃO DE PERÍCIA NA 
ARMA UTILIZADA NO ROUBO. ORDEM PARCIALMENTE CONHECIDA E, NESTA PARTE, DENEGADA. O Superior Tribunal de Justiça sequer examinou o pedido da acusação para que a agravante da reincidência fosse reconhecida. Daí por que não há como o presente habeas corpus ser conhecido nesse ponto. $O$ reconbecimento da causa de aumento de pena prevista no inciso I do $\$ 2^{\circ}$ do art. 157 do Código Penal prescinde da apreensão e da realização de perícia na arma utilizada no roubo. Precedentes. (HC no 84.032, Rel. Min. Ellen Gracie, DJ 30/04/2004, p. 70; e HC n 92.871, Rel. para o acórdão Min. Ricardo Lewandowski, julgado em 04/11/2008). Ordem parcialmente conhecida e, nesta parte, denegada. (STF, $2^{\mathrm{a}}$ T., HC n $\mathrm{n}^{\mathrm{O}}$ 9448, Rel. Min. Joaquim Barbosa, julgado em 11/11/2008, DJ 19/12/2008, grifo nosso).

Portanto, além dos cinco Ministros que votaram no $\mathrm{HC} \mathrm{n}^{\mathrm{o}} 96.099$ pela desnecessidade da apreensão e da perícia na arma de fogo, dois outros Ministros já sinalizaram seus entendimentos na linha majoritária da Suprema Corte.

Voltando ao que ficou discutido no HC $\mathrm{n}^{\mathrm{o}}$ 96.099, observe-se um trecho do voto do Relator Ministro Ricardo Lewandowski, o qual transcrevo por ser elucidativo:

$S e$, por qualquer meio de prova, em especial pela palavra da vítima - reduzida à impossibilidade de resistência pelo agente - ou pelo depoimento de testemunha presencial ficar comprovado o emprego de arma de fogo, esta circunstância deverá ser levada em consideração pelo magistrado na fixação da pena. E no caso sob exame, o depoimento da vítima é firme nesse sentido [...]. Caso o acusado pretenda contraditar o que se contém no acervo probatório ou sustentar a ausência de potencial lesivo da arma empregada para intimidar a vítima, será dele o ônus de produzir tal evidência, nos termos do art. 156 do Código de Processo Penal [...]. Não seria razoável exigir da vítima ou do Estado-acusador comprovar o potencial lesivo da arma, quando o seu emprego tiver sido evidenciado por outros meios de prova, mormente quando esta desaparece por ação do próprio acusado, como usualmente acontece após a prática de delitos dessa natureza. (grifo nosso). 
Oportuna, ainda, foi a justificação no voto para a adoção desse posicionamento:

Não se olvide, de resto, que constitui dever da autoridade judicial não apenas zelar para que os direitos fundamentais do acusado sejam estritamente respeitados, mas também velar para que a norma penal seja aplicada com vistas à prevenção do crime e ao cerceamento da delinqüência. [...] Exigir uma perícia para atestar a potencialidade lesiva da arma de fogo empregada no delito de roubo, ainda que cogitável no plano das especulações acadêmicas, teria como resultado prático estimular os criminosos a desaparecer com elas, de modo a que a qualificadora do art. 157, § $2^{\circ}$, I, do Código Penal dificilmente possa ser aplicada, a não ser nas raras situações em que restem presos em flagrante, empunhando o artefato ofensivo. Significaria, em suma, beneficiá-los com a própria torpeza, hermenêutica essa que não se coaduna com a boa aplicação do Direito. (grifo nosso).

O Ministro Carlos Britto expôs interessante advertência:

Hoje em dia, aluga-se arma para assaltar, praticar crime. Logo depois do crime, a arma de aluguel é devolvida. E, quando é própria, o assaltante faz questão de se desfazer dela para evitar a perícia. Ou seja, se essa tese vingar, ${ }^{1}$ a impunidade vai grassar mais uma vez, dará as cartas. (grifo nosso).

Ainda invocando as lições do julgamento do $\mathrm{HC}^{\circ} \mathrm{n}^{96.099}$, o sempre proverbial Ministro Marco Aurélio ponderou:

[...] já sinalizei convencimento sobre a matéria e chego mesmo a dizer que, a prevalecer a corrente contrária, ${ }^{2}$ a corrente formalizada a uma só voz pela Segunda Turma, o negócio será desaparecer, sempre_e sempre, com a arma utilizada. Arma que, como ressaltou o ministro Carlos Ayres Britto, está, inclusive, no

\footnotetext{
${ }^{1}$ Ou seja, a que não admite o roubo circunstanciado pela arma de fogo sem a devida apreensão.

${ }^{2}$ Ou seja, a que não admite o roubo circunstanciado pela arma de fogo sem a devida apreensão.
} 
mercado de aluguel e, quase sempre, é devolvida de imediato àquele que a disponibilizou. [...] Não estou lembrado do precedente que foi citado e que seria de minha lavra. Mas, se no passado concluí de forma diversa, estou a evoluir, e deve o juiz sempre evoluir tão logo convencido de assistir maior razão [...] à tese rechaçada, repudiada. (grifo nosso).

Prestando atenção nos excertos dos votos acima e interpretandoos, é possível claramente vislumbrar que o STF invoca como fundamento o princípio da proporcionalidade, porém sob uma vertente ainda pouco difundida no Brasil: a da proibição da proteção insuficiente. Realmente, o princípio da proporcionalidade é visto de forma mais destacada sob a modalidade "proibição de excesso". Porém, ultimamente, principalmente com a incursão pioneira de Ingo Wolfgang Sarlet no assunto, a outra vertente vem ganhando terreno na dogmática processual-constitucional brasileira. Ensina Sarlet (2003, p. 86 et seq.) que

[...] o Estado - também na esfera penal - poderá frustrar o seu dever de proteção atuando de modo insuficiente (isto é, ficando aquém dos níveis mínimos de proteção constitucionalmente exigidos) ou mesmo deixando de atuar, hipótese, por sua vez, vinculada (pelo menos em boa parte) à problemática das omissões inconstitucionais. É neste sentido que - como contraponto à assim designada proibição de excesso_- expressiva doutrina e inclusive jurisprudência tem admitido a existência daquilo que se convencionou batizar de proibição de insuficiência (no sentido de insuficiente implementação dos deveres de proteção do Estado e como tradução livre do alemão Untermassverbot). (grifo nosso).

Também incursionaram no assunto, dentre outros, Martha de Toledo Machado (2008), Edilson Mougenot Bonfim (2008, p. 63) e Lenio Luiz Streck (2007).

Para Lenio Streck (2007, p. 100), a doutrina e a jurisprudência nacional, em sua maioria, ainda não se deram conta de que estão trabalhando com o princípio da proporcionalidade sob um único horizonte, ou seja, 
[...] com a hipótese - para mim, a-histórica e atemporal - do garantismo negativo, em que a violação da proporcionalidade se dá pela proibição de excesso (Übermassverbot), esquecendo a relevante circunstância de que o Estado pode vir a violar o princípio da proporcionalidade na bipótese de não proteger suficientemente direitos fundamentais de terceiros (garantismo positivo), representado pela expressão alemã Untermassverbot. (grifo nosso).

Assim, sob a perspectiva da justificativa do voto do Ministro Ricardo Lewandowski no $\mathrm{HC} \mathbf{n}^{\circ} 96.099$ e dos acima colacionados, vê-se que o STF, por seu Pleno, vem dando primazia ao princípio da vedação de proteção insuficiente, porquanto não se pode admitir que o agente, valendo-se de sua própria torpeza, utilize a arma de fogo $\mathrm{e}$, posteriormente, se desfaça dela, inviabilizando a perícia e, por efeito consequencial, afastando, sempre, o roubo circunstanciado pelo emprego de arma. Se o agente, desaparecendo com a arma de fogo empregada no assalto, quiser levantar a tese de inexistência de potencialidade ofensiva do artefato (aduzindo, inclusive, que se utilizou de arma de brinquedo), deve comprovar tal circunstância, obedecendo-se à regra processual de distribuição do ônus da prova (art. 156 do Código de Processo Penal).

Se assim não for, o agente que desse modo agisse restaria sempre impune, sendo que, parafraseando o eminente professor Magalhães Noronha (1996, p. 379), o Estado estaria privilegiando a torpeza e despertando a bilaridade dos sagazes, sendo um verdadeiro partícipe no assalto ao patrimônio alheio.

Por tudo isso, vê-se que a desnecessidade da apreensão e a consequente perícia encontram suas justificações nas dobras do princípio constitucional da proporcionalidade, mais precisamente na vertente da proibição da proteção insuficiente.

Exigir, sempre e incondicionalmente, a apreensão e a perícia da arma de fogo nos crimes de roubo seria despertar a bilaridade dos sagazes... 


\section{Referências bibliográficas}

BONFIM, Edilson Mougenot. Curso de processo penal. 3. ed. São Paulo: Saraiva, 2008.

MACHADO, Martha de Toledo. Proibições de excesso e proteção insuficiente no direito penal: a hipótese dos crimes sexuais contra crianças e adolescentes. São Paulo: Verbatim, 2008.

NORONHA, E. Magalhães. Direito penal. volume 2: dos crimes contra a pessoa; dos crimes contra o patrimônio. 28. ed. rev. e atual. São Paulo: Saraiva, 1996.

SARLET, Ingo Wolfgang. Constituição e proporcionalidade: o direito penal e os direitos fundamentais entre proibição de excesso e de insuficiência. Revista de Estudos Criminais, Porto Alegre, v. 3, n. 12, p. 86-120, out./dez. 2003.

STRECK, Lenio Luiz. Entre Hobbes e Rousseau: a dupla face do princípio da proporcionalidade e o cabimento de mandado de segurança em matéria criminal. In: STRECK, Lenio Luiz (Org.). Direito Penal em tempos de crise. São Paulo: Livraria do Advogado, 2007. p. 75-110. 